\title{
Development of a competency based training programme to support multidisciplinary working in a combined biochemistry/haematology laboratory
}

\author{
R S Woods, W Longmire, M J Galloway, W S A Smellie
}

\begin{abstract}
The aim of this study was to develop a competency based training programme to support multidisciplinary working in a combined biochemistry and haematology laboratory. The training programme was developed to document that staff were trained in the full range of laboratory tests that they were expected to perform. This programme subsequently formed the basis for the annual performance review of all staff. All staff successfully completed the first phase of the programme. This allowed laboratory staff to work unsupervised at night as part of a partial shift system. All staff are now working towards achieving a level of competence equivalent to the training level required for state registration by the Council for Professions Supplementary to Medicine. External evaluation of the training programme has included accreditation by the Council for Professions Supplementary to Medicine and reinspection by Clinical Pathology Accreditation (UK) Ltd. The development of a competency based training system has facilitated the introduction of multidisciplinary working in the laboratory. In addition, it enables the documentation of all staff to ensure that they are fully trained and are keeping up to date, because the continuing professional development programme in use in our laboratory has been linked to this training scheme. This approach to documentation of training facilitated a recent reinspection by Clinical Pathology Accreditation (UK) Ltd.

(F Clin Pathol 2000;53:401-404)
\end{abstract}

South Durham Health Care NHS Trust, Bishop Auckland General Hospital, Cockton Hill Road, Bishop Auckland, County Durham DL14 6AD, UK

R S Woods

W Longmire

M J Galloway

W S A Smellie

Correspondence to: Dr M J Galloway

email: michael.galloway@ btinternet.com

Accepted for publication 11 November 1999
Keyword: multidisciplinary working; competency based training

We have previously reported details of the introduction of multidisciplinary working into our laboratory. This was achieved by fully integrating the working of two previously separate haematology and biochemistry departments. ${ }^{1}$ One of our objectives when developing the multidisciplinary laboratory was to ensure that all staff were fully trained before the commencement of multidisciplinary working. In addition, we wished to see that all staff were documented in terms of their competence for the range of activities that they were expected to perform.
When developing this training strategy we were aware of guidance produced by several professional bodies. This included the Clinical Pathology Accreditation (UK) Ltd handbook. ${ }^{2}$ Standard B2 refers specifically to the standard of training that staff working in a multidisciplinary laboratory should achieve. In particular, the staff should be trained to standards set by the Council for Professions Supplementary to Medicine (CPSM). This of course does not apply to medical laboratory assistants (MLAs), and an alternative approach is required for these individuals. The Institute of Biomedical Science (IBMS) has also produced guidance on training of biomedical scientists. ${ }^{3}$ In this guidance document, specific reference is given to training for multidisciplinary departments. This guidance document was also reviewed in the preparation of our training programme. The appropriateness of ensuring that staff are fully trained, competent, and continually keeping up to date has recently been emphasised in the government's documents on clinical governance. ${ }^{45}$ One key component of clinical governance is continuing professional development (CPD). We felt that it would be essential as part of our training programme to ensure that all staff, once they had been trained and documented to be competent, should also be keeping up to date. Therefore, this paper outlines our approach to the development of a competency based training scheme to support multidisciplinary working in a combined biochemistry and haematology laboratory.

\section{Methods}

Two phases to the training programme were developed.

PHASE 1

This phase included training on the operation of automated equipment and the performance of skilled manual procedures. There were three learning phases that included: (1) an initial familiarisation period; (2) a period of close supervision of the use of equipment etc, including theoretical instructions; (3) experience of daily use of equipment etc, with assistance readily available when requested.

This part of the training was initially undertaken by internal rotation between the two existing departments followed by full cross training. Documentation of competency was developed so that by the end of this phase all staff who were to work in the multidisciplinary department were expected to be competent in 


\section{Competency scoring}

\section{1-3 Medical Laboratory Assistant.}

1-4 Haematology Nurse Specialist.

1-6 Medical Laboratory Scientific Officer. Level 3 is the minimum leve required to work on the partial shift system that includes an out of hours service. Level 6 is equivalent to training to the standards set by the Council for Professions Supplementary to Medicine.

1. Familiar with test but undergoing training.

2. Able to produce routine results under close supervision.

3. Able to produce routine normal results ready for reporting under distance supervision.

4. Able to produce routine results unsupervised. Limited problem solving.

5. Able to produce routine results unsupervised for reporting. Able to produce abnormal results ready for reporting after confirmation. Some specialist knowledge.

6. Able to provide expert supervision. Able to report abnormal and normal results with recognition and understanding of their clinical implications.

Figure 1 A competency based scoring system was developed for each test and standard operating procedure. Individual members of staff were assessed using this scoring system.

all tests that they would be required to perform. Initially, this was limited to all routine tests that were required during the day and all tests that were performed out of hours. At the end of this phase it was intended that staff who had failed to achieve the necessary competency would be reviewed and a further programme of training would then be put in place to support these staff. All staff who achieved competency at this point were allowed to work in the multidisciplinary department, including providing a service out of hours. At this stage, back up cover was available from state registered medical laboratory scientific officers (MLSOs) in the opposite speciality because staff were required to work by themselves at night as part of a partial shift system. The partial shift system included normal working hours from 09.00 to 17.00 , followed by one MLSO and one MLA working the period from 17.00 to 21.00 to cover urgent work and samples from a second general practitioner van run. During this time, some routine batched work was also performed. A reduced service was then offered from 21.00 to 24.00. The period from 24.00 to 09.00 is designated as on call and one MLSO provides a multidisciplinary service during this time. As described above, when a MLSO was working this on call period, there was always a second on call MLSO from the opposite speciality available to provide back up.

A competency scoring system was developed for each test and standard operating procedure (fig 1). The degrees of competency that were to be achieved depended on the grade of staff; that is, MLA, MLSO, or haematology nurse specialist. The target score for MLSOs was that they were expected to reach a minimum score of 3 to be allowed to work independently in the combined laboratory. However, this did not equate to training to CPSM standards; therefore, at night back up provision was always provided from the opposite speciality if the MLSO was working alone. When the MLSO had reached a target score of 6 this was deemed to be equivalent to CPSM state registration standards. Staff were asked to self declare their competency on an annual basis using this scoring system. They were then assessed objectively in performing the test by an MLSO at level 3 or 2. Any gaps in competency identified by this assessment indicated that a further period of training was required for that individual. This documentation was to form part of a training portfolio for each individual.

PHASE 2

After successful completion of phase 1, a further training programme was then developed based on the log books produced by CPSM. This training covered in particular the areas requiring complex skills, such as subjective and interpretative skills, together with the related theoretical knowledge. The aim was for staff to be trained to the level approved by CPSM for state registration. Progress towards this objective was to be assessed on an annual basis as part of an individual performance review of each member of staff. The performance assessment was to be documented for each member of staff for each test that they are required to perform. Inadequate performance for that level of test would immediately initiate a further training programme for that member of staff.

TRAINING SUPPORT

Several other programmes were put in place to develop a continuing professional development programme for the staff. These comprised a variety of training packages, including external courses, particularly for blood transfusion, linked to in house continuing professional development accredited lectures. In addition, computer based training programmes and continuing professional development questionnaires were developed around the areas required for training in the CPSM log books.

\section{EVALUATION}

The success of the training programme was evaluated by both internal and external assessment. The internal assessment included monitoring the number of staff who achieved full competency at the end of the first phase of the training programme. The external assessment included an inspection by CPSM to document that the programmes were suitable for training. The laboratory was also due to be revisited as part of the Clinical Pathology Accreditation (UK) Ltd cycle of inspections. Both departments had been fully accredited by Clinical Pathology Accreditation (UK) Ltd since 1992, before their merger in 1996. The reinspection of the laboratory occurred 18 months after 


\begin{tabular}{|c|c|c|c|c|c|c|}
\hline \multicolumn{2}{|c|}{$\begin{array}{l}\text { Haematology/Biochemistry } \\
\text { training assessment sheet }\end{array}$} & \multicolumn{2}{|c|}{$\begin{array}{l}\text { Name: } \\
\text { Position: }\end{array}$} & \multicolumn{3}{|c|}{ MLSO } \\
\hline \multirow[b]{2}{*}{ Blood bank } & \multirow[b]{2}{*}{ Appropriate SOPs } & \multirow{2}{*}{$\begin{array}{l}\text { Target } \\
\text { score }\end{array}$} & \multicolumn{4}{|c|}{ Yearly assessment $1-6$} \\
\hline & & & $96-7$ & $97-8$ & $98-9$ & $99-00$ \\
\hline Routine checks & ВB01, 02, 03, 26, Н34 & 6 & 3 & 4 & & \\
\hline Blood groups & BB 05,28 & 6 & 3 & 5 & & \\
\hline Crossmatching & $\mathrm{BB} 06,07,08,18,22,28,30$ & 6 & 3 & 5 & & \\
\hline Stock control & BB04, 11, 22 & 6 & 3 & 5 & & \\
\hline Kleihauer & BB10, 11 & 6 & 3 & 4 & & \\
\hline Computer & B04, 0507, 13 17, 18, 20, 22, H36 & 6 & 4 & 4 & & \\
\hline Platelets & $\mathrm{BB} 4,13$ & 6 & 3 & 5 & & \\
\hline FFP & BB4, 17,29 & 6 & 3 & 5 & & \\
\hline Du & BB21 & 6 & 3 & 5 & & \\
\hline DCT & BB21 & 6 & 3 & 5 & & \\
\hline Antibody ID & BB16 & 6 & 2 & 4 & & \\
\hline Major incident & BB20 & 6 & 3 & 4 & & \\
\hline Emergency proced & $\mathrm{BB} 8,20$ & 6 & 3 & 4 & & \\
\hline Immune antibodies & BВ09 & 6 & 2 & 3 & & \\
\hline Batched products & BB04 & 6 & 3 & 3 & & \\
\hline Transfusion reactio & BB15 & 6 & 2 & 4 & & \\
\hline Autologous blood & BB24 & 6 & 2 & 3 & & \\
\hline Flying squad & BB25 & 6 & 3 & 5 & & \\
\hline Sample storage & $\mathrm{BB} 06,07,08,18,22,28,30$ & 6 & 3 & 5 & & \\
\hline Fridge failure & BB27 & 6 & 3 & 3 & & \\
\hline Irradiated/CMV blo & BB30 & 6 & 3 & 4 & & \\
\hline SHOT & BB23 & & & & & \\
\hline \multicolumn{7}{|l|}{ EKTACHEM E700 } \\
\hline Glucose & B32, В33, в34 & 6 & 6 & 6 & & \\
\hline CUE & B25, B62, B55, B48, B19, B17 & 6 & 6 & 6 & & \\
\hline LFT & B13, B6, B2, B30, B52, B3, B12 & 6 & 6 & 6 & & \\
\hline Cenz & B24, B10 & 6 & 6 & 6 & & \\
\hline Bone & $\mathrm{B} 3, \mathrm{~B} 15, \mathrm{~B} 6, \mathrm{~B} 47, \mathrm{~B} 43$ & 6 & 6 & 6 & & \\
\hline Lipids & B20, B60, B20.1 & 6 & 6 & 6 & & \\
\hline Iron studies & В38, В39 & 6 & 6 & 6 & & \\
\hline Amylase & B7 & 6 & 6 & 6 & & \\
\hline LDH & B40 & 6 & 6 & 6 & & \\
\hline Theophylline & B56 & 6 & 6 & 6 & & \\
\hline Paracetamol & B45 & 6 & 6 & 6 & & \\
\hline Salicylate & B54 & 6 & 6 & 6 & & \\
\hline Lithium & B42 & 6 & 6 & 6 & & \\
\hline Alcohol & B5 & 6 & 6 & 6 & & \\
\hline CSF & B33, B51 & 6 & 6 & 6 & & \\
\hline Urine electrolytes & B79 & 6 & 6 & 6 & & \\
\hline \multicolumn{7}{|c|}{248 blood gas analyser } \\
\hline Operation & B31 & 6 & 6 & 6 & & \\
\hline
\end{tabular}

Figure 2 An example of a training record for one member of staff (biochemistry medical laboratory scientific officer) showing the result of yearly assessments that were included as part of the annual performance review.

merger in 1998. In addition, we have voluntarily arranged over the past five years for our blood transfusion service to be inspected on an annual basis by the quality assurance manager from the regional transfusion centre. These inspections include an audit against Clinical Pathology Accreditation (UK) Ltd standards for the transfusion laboratory.

\section{Results}

PHASE 1

An example is given in fig 2 of a competency assessment of an MLSO in biochemistry who was being trained in haematology. The competency assessment has confirmed that the MLSO remains competent to CPSM standards for biochemistry tests and was working towards level 6 competency for blood bank procedures. Progress in the competence of that person has been documented since training for haematology skills commenced. The nurse specialists linked to the clinical haematology service were included in the training programme because these nurses perform full blood counts and internationl normalised ratios to support oncology and anticoagulant clinics. Using this target scoring system, a competency profile was developed for each member of staff. Subsequently, it was found necessary to attach training records to each standard operating procedure. This was to ensure that when standard operating procedures were modified appropriate training had taken place and was seen to have been documented. At the end of the first phase, a total of 19 members of staff were documented to be fully competent in the range of tests they were expected to perform. One member of staff initially did not participate in the competency based training. That member of staff was then informed that he would not be able to work in the partial shift system that included an out of hours service. After further discussions, he then participated in the training and was documented to be fully competent. We therefore achieved $100 \%$ success in the competency based training for all staff. This phase of the training programme was completed in 12 months.

\section{PHASE 2}

Phase 2 of the programme is still evolving. All members of staff have an annual performance review undertaken by a technical manager at MLSO level 3. An example of the documentation of this assessment is shown in fig 2. As described above, once staff have achieved a competency level of 6 for all tests we would then consider them eligible to be examined to CPSM standards. All staff are working towards this objective, although no member of staff has reached that stage. Despite this, the staff are confident to work alone at night and rarely require the backup support from the opposite speciality that is always provided.

\section{EVALUATION}

The training programmes that we introduced were accredited by CPSM for training. After the reinspection by Clinical Pathology Accreditation (UK) Ltd, as part of a second cycle visit, the training programmes have also been documented to be satisfactory and to meet with Clinical Pathology Accreditation (UK) Ltd standards. Similarly, our training programmes have also been approved following our annual inspection by the regional transfusion centre.

\section{Discussion}

The merger of our biochemistry and haematology departments was one of the factors that stimulated us to review how we could document the competency of MLSO staff working in the combined department. We recognised that this would be a requirement for our reinspection by Clinical Pathology Accreditation (UK) Ltd. Furthermore, one of the key aspects of clinical governance is that all professionals undertake a process of life long learning, so that they can show they are keeping up to date and are competent to practice. ${ }^{4}$ 
The model that we have developed is similar to that of the practice audit model that has been described elsewhere. ${ }^{6}$ In this case, the process of identifying requirements of a role linked with audit and the development of a continuing development programme was assessed in a microbiology laboratory in the Wessex region. We are not aware of any other publications relating to the development of such a model applied to a combined biochemistry and haematology department in the UK.

One of the reasons that our model has been successful in developing a training programme for multidisciplinary working is the link between the training programme and continuing professional development. We have gained IBMS accreditation for a number of activities that support continuing professional development, including regular lectures, external courses, and practice based bench working sessions. Currently, continuing professional development is not a mandatory requirement for state registration of MLSOs. In the absence of this, our documented competency methods do indicate that a member of staff is keeping up to date and is competent to practice.

Within our system, a competency level of 3 is required to work on the partial shift system. This includes working alone at night. Until the member of staff obtains a level 6 then there is always back up provided from the opposite speciality. Each of the competency forms is part of the training portfolio for that member of staff. However, additional documentation is also required for each standard operating procedure. The reason for this is that if a standard operating procedure is altered then appropriate training must be documented to ensure that all members of staff are keeping up to date in that procedure.

Assessment of employee competency in pathology still seems unusual in the UK. In contrast, a Q-probe study published by the College of American Pathologists ${ }^{7}$ indicated that $89.8 \%$ of laboratories that participated in this study had a written competency plan. Most participants in this study $(97.5 \%)$ were located in the USA. In this study it was noted that $84.9 \%$ include a competency assessment as part of the yearly performance review. This has also been our approach. Our competency based system primarily relates to skills required in the performance of laboratory tests. As documented in the Q-probe study, ${ }^{7}$ employees must also be knowledgeable and skilled in communication, teaching and training, supervision, and management. We will need to extend our competency based training programme to include these areas.

1 Smellie WSA, Galloway MJ, Longmire W, et al. Introduction of multidisciplinary working in pathology: a successful Clinician in Management 1998; 7:216-20.

2 Clinical Pathology Accreditation (UK) Ltd. Accreditation handbook. Sheffield: CPA, 1996.

3 Institute of Biomedical Science. Professional pathways of biomedical scientists: general guidance for professional education and training. London: IBMS, 1997.

4 Secretary of State for Health. The new NHS. Modern, dependable. London: HMSO, 1997.

5 Secretary of State for Health. A first class service: quality in the new NHS. London: Department of Health, 1998.

6 O'Hara SP, Renton-Skinner P, Thorne AJ. Evolution of the species 1: competency assessment-playing with fire. Biomedical Scientist 1998;42:836-9.

7 Howanitz PJ, Valenstein PN, Fine G. Employee competency evaluation Q-probe 96-04. Northfield, Illinois: College of American Pathologists, 1997. 